\title{
Remoción de la hemoglobina por adsorción sobre nanopartículas magnéticas de $\mathrm{Fe}_{3} \mathrm{O}_{4} / \mathrm{TiO}_{2}$
}

\author{
María Eulalia Vanegas, Nancy García, Verónica Vázquez, Diana Moscoso \\ Centro de Estudios Ambientales (CEA), Universidad de Cuenca, Campus Quinta Balzay, Av. Víctor \\ Manuel Albornoz, Cuenca, Ecuador. \\ Autor para correspondencia: eulaliavanegas@gmail.com \\ Fecha de recepción: 24 de junio 2014 - Fecha de aceptación: 10 de agosto 2014
}

\begin{abstract}
RESUMEN
La remoción de la hemoglobina $(\mathrm{Hb})$ por adsorción de la proteína sobre nanopartículas (Nps) magnéticas de $\mathrm{Fe}_{3} \mathrm{O}_{4} / \mathrm{TiO}_{2}$ (núcleo/coraza) aplicando un campo magnético externo, fue investigada mediante espectroscopia ultravioleta en el rango del ultravioleta y visible (UV-VIS). Durante la etapa de contacto de las Nps con la $\mathrm{Hb}$ se varió la concentración de las Nps y la temperatura, complementariamente durante la etapa de remoción del complejo $\mathrm{Fe}_{3} \mathrm{O}_{4} / \mathrm{TiO}_{2}-\mathrm{Hb}$ se varió la intensidad del campo magnético externo. Con una concentración inicial de $\mathrm{Nps}$ de $8 \mathrm{mg} \mathrm{ml}^{-1}$, el valor de la absorbancia del sobrenadante disminuye en un $11 \%$ con respecto a la solución inicial de $\mathrm{Hb}\left(0,8 \mathrm{~g} \mathrm{l}^{-1}\right)$ y al aumentar en un 50\% la concentración de $\mathrm{Nps}$, el valor disminuye hasta un 17\%. Al incrementar la temperatura de 25 a $35^{\circ} \mathrm{C}$ disminuye la adsorción de la $\mathrm{Hb}$ pero no se observa indicios de desnaturalización de la misma. Durante la etapa de remoción del complejo $\mathrm{Fe}_{3} \mathrm{O}_{4} / \mathrm{TiO}_{2}-\mathrm{Hb}$, al incrementar la fuerza magnética se logra una caída en la intensidad de la absorbancia, casi un 30\%. Finalmente, se determinó la demanda bioquímica de oxígeno $\left(\mathrm{DBO}_{5}\right)$ de la solución inicial de $\mathrm{Hb}$ y del sobrenandante, el valor para la solución inicial de $\mathrm{Hb}$ fue de $100 \mathrm{mg} \mathrm{ml}^{-1}$ y los resultados obtenidos para todas las soluciones tratadas fueron inferiores $\left(<62 \mathrm{mg} \mathrm{ml}^{-1}\right)$ verificando el impacto que tuvo el uso de las Nps magnéticas de $\mathrm{Fe}_{3} \mathrm{O}_{4} / \mathrm{TiO}_{2}$ en la remoción de la $\mathrm{Hb}$.
\end{abstract}

Palabras clave: Hemoglobina, adsorción, nanopartículas magnéticas, espectroscopía UV-VIS.

\begin{abstract}
The removal of Hemoglobin $(\mathrm{Hb})$ by protein adsorption on magnetic nanoparticles (Nps) of $\mathrm{Fe}_{3} \mathrm{O}_{4} / \mathrm{TiO}_{2}$ (core/shell), applying an external magnetic field, was investigated using ultraviolet spectroscopy in the ultraviolet and visible range (UV-VIS). The Nps concentration and temperature was varied during the contact step between $\mathrm{Nps}$ and $\mathrm{Hb}$. Complementary, the intensity of the external magnetic field was varied during the removal of the $\mathrm{Fe}_{3} \mathrm{O}_{4} / \mathrm{TiO}_{2}-\mathrm{Hb}$ complex. With an initial Nps concentration of $8 \mathrm{mg} \mathrm{ml}^{-1}$, the absorbance of the supernatant solution showed a decrease of $11 \%$ with respect to the initial $\mathrm{Hb}$ solution $\left(0,8 \mathrm{~g} \mathrm{l}^{-1}\right)$, and a decrease of $17 \%$ when the Nps concentration was increased with 50\%. A reduction of the absorbtion of $\mathrm{Hb}$ was observed by increasing the temperature from 25 to $35^{\circ} \mathrm{C}$, but no evidence of denaturalization was found. During the $\mathrm{Fe}_{3} \mathrm{O}_{4} / \mathrm{TiO}_{2}-\mathrm{Hb}$ complex removal step, the absorption intensity nearly decreased $30 \%$ by increasing the strength of the magnetic field. Finally, the biochemical oxygen demand $\left(\mathrm{BOD}_{5}\right)$ of the initial $\mathrm{Hb}$ solution and supernatant was determinated. The value of the initial $\mathrm{Hb}$ solution was $100 \mathrm{mg} \mathrm{ml}^{-1}$ and the results for all treated solutions were lower $\left(<62 \mathrm{mg} \mathrm{ml}^{-1}\right)$ reflecting the impact of magnetic Nps in the removal of $\mathrm{Hb}$.
\end{abstract}

Keywords: Hemoglobin, adsorption, magnetic nanoparticles, UV-VIS spectroscopy. 


\section{INTRODUCCIÓN}

La nanotecnología en la última década ha llamado mucho la atención debido a que los nanomateriales -materiales que están en la escala nanométrica- poseen propiedades funcionales específicas diferentes a las propiedades de los átomos o de materiales macroscópicos, por lo que tienen un amplio rango de aplicaciones, incluyendo el área de catálisis, microprocesadores, sensores químicos y biológicos (Salimi y col., 2007). Dentro de los materiales nanoestructurados, Beydoun y col. (2000) fueron los primeros en estudiar la síntesis de nanopartículas (Nps) magnéticas tipo centro/coraza (core/shell) de $\mathrm{Fe}_{3} \mathrm{O}_{4} / \mathrm{TiO}_{2}$ bajo diferentes tratamientos térmicos y evaluar posteriormente su efecto en las propiedades fotocatalíticas, con respecto al incremento de la temperatura. Los autores concluyen una clara disminución en la fotoactividad. Además, Beydoun y Amal (2002) mencionan que la adsorción de compuestos orgánicos en la superficie del fotocalizador es importante para una oxidación efectiva.

La preparación de polímeros de impresión molecular se ha desarrollado exitosamente para moléculas pequeñas y actualmente existe gran interés en el reconocimiento de macromoléculas (proteínas) en procesos de bio-enrequecimiento y separación. El uso de $\mathrm{Nps}$ de $\mathrm{Fe}_{3} \mathrm{O}_{4}$ encapsuladas dentro de una matriz polimérica es un ejemplo de polímeros de impresión molecular magnéticos que conservan su sensibilidad magnética y presentan una rápida adsorción de hemoglobina $(\mathrm{Hb})$ (Kan y col., 2010). En bionanotecnología, se requiere el estudio del fenómeno de adsorción de proteínas sobre la superficie para el mejoramiento en la fabricación de biosensores, aparatos bioelectrónicos, biocélulas de combustión y en la síntesis de nuevos materiales híbridos (Jin y col., 2012). Las condiciones de adsorción o inmovilización de moléculas sobre una superficie desde una solución dependen de la composición química y estructura del sólido, así como, de la naturaleza de la solución (Zhang y col., 1999). Las propiedades de las proteínas adsorbidas tienen relación con el grado de afinidad entre las superficies del sólido y las proteínas. Una desnaturalización inesperada de las proteínas adsorbidas puede ocurrir ocasionalmente dependiendo del entorno del soporte (Matsui y col., 2008).

Dentro del área medioambiental, las aguas residuales generadas en la actividad productiva de mataderos e industria de productos cárnicos procesados contienen un alto nivel de material orgánica, donde la sangre constituye el principal componente en la descarga (Carawan y col., 1979). La no remoción de este contaminante y la posterior descarga inadecuada en ríos, pueden causar serios problemas ecológicos. Los glóbulos rojos y hematíes constituyen el 96\% de los elementos semisólidos de la sangre. La $\mathrm{Hb}$ presente en los glóbulos rojos es una proteína tetramérica de peso molecular $64500 \mathrm{~g} \mathrm{~mol}^{-1}$ y de forma casi esférica, con dimensiones $6,4 \mathrm{~nm} \times 5,5 \mathrm{~nm} \times 5,0 \mathrm{~nm}$. El estudio de la adsorción de la $\mathrm{Hb}$ en la superficie de las $\mathrm{Nps}$ de $\mathrm{Fe}_{3} \mathrm{O}_{4} / \mathrm{TiO}_{2}$ y/o posterior remoción es de relevante importancia, ya que representa una alternativa para su utilización en tratamientos de efluentes por permitir reunir las propiedades derivadas del $\mathrm{TiO}_{2}$ utilizado en la degradación o absorción de toda clase de contaminantes orgánicos e inorgánicos presentes en el aire y en el agua (Carp y col., 2004) y la facilidad que dispondrían las $\mathrm{Nps}$ de $\mathrm{Fe}_{3} \mathrm{O}_{4}$ debido a su comportamiento superparamagnético de ser transportadas a una zona de interés a través de la aplicación de un campo magnético externo (Beydoun y col., 2000; Maity y Agrawal, 2007).

La espectroscopía ultravioleta en el rango del ultravioleta y visible (UV-VIS) es uno de los métodos esenciales para investigar la estructura y funcionalidad de moléculas. Además, esta técnica permite valorar cuantitativamente diferentes analitos como macromoléculas biológicas; por ejemplo la variación en la concentración de Hb. Por otro lado, la medición de la demanda bioquímica de oxígeno (DBO) determina los requerimientos relativos de oxígeno en desagües, efluentes y aguas contaminadas. La DBO es proporcional a la cantidad de materia orgánica presente y por lo tanto es una medida de la fuerza de los residuos o desechos y permite calcular los efectos de las descargas de estos sobre la calidad de las aguas de los cuerpos receptores. Este ensayo permite a su vez valorar la eficiencia de sistemas de tratamiento de aguas en términos de remoción de DBO (American Water Works Association, 1999; Standard Methods Committee, 2001).

En el presente trabajo se presenta el estudio por espectroscopía UV-VIS de la remoción de la $\mathrm{Hb}$ por adsorción o inmovilización de la proteína sobre las Nps del tipo $\mathrm{Fe}_{3} \mathrm{O}_{4} / \mathrm{TiO}_{2}$ y posterior separación del complejo $\mathrm{Fe}_{3} \mathrm{O}_{4} / \mathrm{TiO}_{2}-\mathrm{Hb}$ mediante un campo magnético externo. Durante el período de contacto 
de la proteína con las Nps en la parte inicial de las pruebas se varió la concentración de las Nps y la temperatura. Mientras que en la parte final de la prueba se evaluó la remoción del complejo $\mathrm{Fe}_{3} \mathrm{O}_{4} / \mathrm{TiO}_{2}-\mathrm{Hb}$ con el aumento de la intensidad campo magnético externo. Como información complementaria se determinó la $\mathrm{DBO}_{5}$ de todas las soluciones y se relacionó con los valores de UVVIS.

\section{MATERIALES Y MÉTODOS}

\subsection{Reactivos}

Las Nps de $\mathrm{Fe}_{3} \mathrm{O}_{4} / \mathrm{TiO}_{2}$ fueron sintetizadas por el método combinado que involucra la co-precipitación química y proceso sol-gel. La descripción de la síntesis y caracterización ha sido reportada previamente (Vanegas y col., 2014). La Hb (sangre bovina) fue adquirida a la compañía Sigma y usada sin ningún tratamiento. Para la preparación de las diferentes soluciones de $\mathrm{Hb}$ se utilizó el buffer $0,1 \mathrm{M}$ fosfato $\mathrm{pH}$ 6,5. Para obtener este buffer se disolvió $13,8 \mathrm{~g}$ de $\mathrm{NaH}_{2} \mathrm{PO}_{4} \cdot \mathrm{H}_{2} \mathrm{O}$ (para análisis, compañía Merck) en $900 \mathrm{ml}$ de agua desionizada con conductividad específica de $0,03 \mu \mathrm{s} \mathrm{cm}^{-1}$. Se ajustó el pH usando una solución de $400 \mathrm{~g} \mathrm{l}^{-1}$ de $\mathrm{NaOH}$ (GR, compañía Merck) y se diluyó hasta completar $1000 \mathrm{ml}$.

\subsection{Ensayo para estudiar la remoción de Hb mediante la adsorción de la proteína sobre Nps de $\mathrm{Fe}_{3} \mathrm{O}_{4} / \mathrm{TiO}_{2}$ y aplicación de un campo magnético externo}

Se colocaron en un matraz $50 \mathrm{ml}$ de la solución de $\mathrm{Hb}$ en buffer pH 6,5 a una concentración de 0,8 $\mathrm{g} \mathrm{l}^{-1}$. Por otro lado, se pesaron las Nps de $\mathrm{Fe}_{3} \mathrm{O}_{4} / \mathrm{TiO}_{2}\left(8\right.$ y $\left.12 \mathrm{mg} \mathrm{l}^{-1}\right)$, se adicionaron a la solución de $\mathrm{Hb}$ y se colocaron en el shaker a 25 y $35^{\circ} \mathrm{C}$ por 24 horas a $110 \mathrm{rpm}$ (Zhang y col., 2011). Después del tiempo programado se apartó y se colocó cerca de un y dos imanes por un tiempo determinado $(1,24$ y 48 horas). Todas las mediciones de UV-VIS se realizaron en el rango de 340-600 nm (Spectrophotometer 1100). Debido a que la absorbancia UV-VIS de las soluciones es directamente proporcional a la concentración de la $\mathrm{Hb}$ (Topoglidis y col., 2001), la remoción de la Hb por las Nps de $\mathrm{Fe}_{3} \mathrm{O}_{4} / \mathrm{TiO}_{2}\left(\mathrm{Hb}\right.$ adsorbida sobre las $\mathrm{Nps}$ de $\left.\mathrm{Fe}_{3} \mathrm{O}_{4} / \mathrm{TiO}_{2}\right)$ se relaciona con la señal obtenida a 406 $\mathrm{nm}$ de la cantidad libre de $\mathrm{Hb}$ de la solución del sobrenadante y la cantidad de $\mathrm{Hb}$ de la solución inicial (Kan y col., 2010). La solución del sobrenadante fue posteriormente utilizada para la determinación de la DBO.

\subsection{Determinación de la $\mathrm{DBO}_{5}$}

Preparación del microorganismo

La cepa de Escherichia Coli ATCC (E.Coli) fue donada por la Facultad de Ciencias Químicas de la Universidad de Cuenca, la cual se almacenaba en criotubos a una temperatura $-80^{\circ} \mathrm{C}$. Al estar en estas condiciones fue necesario realizar la siembra e incubación del microorganismo. Para la siembra de las bacterias se preparó el medio de cultivo de agar nutritivo $\left(20 \mathrm{~g} \mathrm{l}^{-1}\right)$ y se esterilizó en autoclave a $121^{\circ} \mathrm{C}$ por 15 min. Se retiró del autoclave y se procedió a colocar el medio en las cajas Petri previamente esterilizadas. Una vez solidificado el medio de cultivo se realizó la siembra del microorganismo y su incubación en el shaker a $37^{\circ} \mathrm{C}$ por 48 horas. Finalmente, de las placas se tomó una colonia $(50 \mathrm{mg})$ y se disolvió en $100 \mathrm{ml}$ de agua destilada y se agitó posteriormente en el shaker por 2 horas a temperatura ambiente. Pruebas preliminares realizadas para optimizar la concentración del microorganismo se concluyó que una dilución al 100\% es necesaria para obtener buenos resultados en la $\mathrm{DBO}_{5}$. La conservación posterior de las cepas se realizó a $4^{\circ} \mathrm{C}$.

\section{Preparación y verificación del agua de dilución}

Se prepararon las siguientes soluciones: 1) se disolvió $22,5 \mathrm{~g}$ de $\mathrm{MgSO}_{4} \cdot 7 \mathrm{H}_{2} \mathrm{O}$ y se aforó a 1 litro; 2) se disolvió $27,5 \mathrm{~g}$ de $\mathrm{CaCl}_{2}$ y se aforó a 1 litro; y 3) se disolvió $0,25 \mathrm{~g} \mathrm{de} \mathrm{FeCl}_{3} .6 \mathrm{H}_{2} \mathrm{O}$ y se aforó a 1 litro. Para la preparación del agua de dilución por cada litro de agua desionizada se adicionó $1 \mathrm{mg}$ de 
las soluciones de sulfato de magnesio, cloruro de calcio, cloruro férrico. El agua de dilución se preparó justo antes de cada prueba, se llevó a una temperatura de $20^{\circ} \mathrm{C}$ y se saturó con oxígeno por burbujeo. Para la verificación del agua de dilución se tomó $300 \mathrm{ml}$, se determinó el oxígeno disuelto (OD). Todas las medidas de OD se realizaron con el sensor Oakton Waterproof DO 300 meter. Se colocó en las botellas Winkler y se tapó herméticamente mediante sello de agua. La muestra se incubó por 5 días a $20^{\circ} \pm 1^{\circ} \mathrm{C}$ y se determinó el OD final.

\section{Control de inóculo}

Se colocó el agua de dilución en un frasco graduado $(300 \mathrm{ml})$, se adicionó $1 \mathrm{ml}$ del inóculo de E.Coli, se homogenizó con una varilla y se midió el OD. La muestra se colocó posteriormente en botellas Winkler, se tapó e incubó. Finalmente se determinó el OD final.

\section{Chequeo con hemoglobina}

Se tomó un volumen de $15 \mathrm{ml}$ de la solución de $\mathrm{Hb}$ en buffer $\mathrm{pH}$ 6,5 a una concentración de $0,8 \mathrm{~g} \mathrm{l}^{-1}$, se adicionó $1 \mathrm{ml}$ del inóculo de E.Coli, y se completó con agua de dilución hasta un volumen de 300 $\mathrm{ml}$. Se midió el OD y las muestras se colocaron en botellas Winkler y se taparon. Luego de un período de 5 días de incubación se les determinó el OD final.

\section{Prueba de las muestras}

Se recuperó el sobrenadante de las soluciones de $\mathrm{Hb}$ tratadas previamente con $\mathrm{Nps}$ de $\mathrm{Fe}_{3} \mathrm{O}_{4} / \mathrm{TiO}_{2}$ y removidas bajo la acción de un campo magnético externo. Se tomaron $15 \mathrm{ml}$ de la muestra tratada, se completó con agua de dilución hasta $\operatorname{los} 300 \mathrm{ml}$, se adicionó $1 \mathrm{ml}$ del inóculo de E. Coli, y se midió el OD inicial. Las muestras se colocaron en botellas Winkler, se taparon e incubaron por 5 días. Al término de este período, se determinó el OD final. Soluciones de control del agua de dilución y de la $\mathrm{Hb}$ fueron preparadas para cada prueba.

\section{Cálculos}

Para la determinación de la $\mathrm{DBO}_{5}$ es necesario tomar en consideración la actividad metabólica endógena del microorganismo; y por lo tanto, se utilizó la siguiente ecuación:

$$
\mathrm{DBO}_{5}\left(m g l^{-1}\right)=\frac{\left(\mathrm{D}_{1}-\mathrm{D}_{2}\right)-\left(\mathrm{B}_{1}-\mathrm{B}_{2}\right)}{\mathrm{P}}
$$

donde: $\mathrm{D}_{1}$ es el OD de la muestra inmediatamente después de la preparación ( $\left.\mathrm{mg} \mathrm{l}^{-1}\right), \mathrm{D}_{2}$ es el OD de la muestra después de 5 días de incubación a $20^{\circ} \mathrm{C}\left(\mathrm{mg} \mathrm{l}^{-1}\right), \mathrm{B}_{1}$ es el OD del control del inóculo de $E$. Coli antes de la incubación $\left(\mathrm{mg} \mathrm{l}^{-1}\right), \mathrm{B}_{2}$ es el OD del control del inóculo de $E$. Coli después de la incubación $\left(\mathrm{mg}^{-1}\right)$ y $\mathrm{P}$ es la fracción volumétrica decimal de la muestra empleada.

\section{RESULTADOS Y DISCUSIÓN}

La absorción o inmovilización de la $\mathrm{Hb}$ sobre las Nps magnéticas recubiertas depende de la carga superficial de las mismas. En este caso al tratarse de $\mathrm{Nps}$ de $\mathrm{Fe}_{3} \mathrm{O}_{4} / \mathrm{TiO}_{2}$, dependerá de la carga superficial existente en la coraza de $\mathrm{TiO}_{2}$. Un parámetro importante para evaluar la estabilidad de una dispersión es a través del potencial zeta, el cual es función de la carga superficial de las partículas. Cuando el potencial zeta es cercano a cero o punto isoeléctrico, las partículas tienden a aglomerarse. A valores positivos o negativos del potencial zeta las partículas tienden a repelerse y no se produce la aglomeración (Mandzy y col., 2005). El punto isoeléctrico es el $\mathrm{pH}$ en el cual el potencial zeta es cero. Para una solución acuosa de $\mathrm{TiO}_{2}$ (anastasa) está reportado que el punto isoeléctrico tiene un valor 
entre 6,1 y 6,3 (Topoglidis y col., 2001), por lo tanto a un $\mathrm{pH}$ superior la superficie de las $\mathrm{Nps}$ de $\mathrm{TiO}_{2}$ está cargada negativamente. Por otro lado, el punto isoeléctrico de la $\mathrm{Hb}$ es de 6,8; lo que significa que a $\mathrm{pH}$ inferiores la $\mathrm{Hb}$ está cargada positivamente. Se tuvo en cuenta esta condición y se trabajó a pH 6,5 , donde se esperaría un máximo de adsorción debido a las fuertes interacciones electrostáticas contrapuestas existentes entre la $\mathrm{Hb}$ y las $\mathrm{Nps}$ de $\mathrm{Fe}_{3} \mathrm{O}_{4} / \mathrm{TiO}_{2}$ (Kan y col., 2010). Además, trabajar con buffer de fosfato de potasio a pH 6,5 minimiza una posible desnaturalización de la $\mathrm{Hb}$.

\subsection{Efecto de la concentración de las $\mathrm{Nps}$ de $\mathrm{Fe}_{3} \mathrm{O}_{4} / \mathrm{TiO}_{2}$ en la adsorción de la $\mathrm{Hb}$ y posterior remoción del complejo $\mathrm{Fe}_{3} \mathrm{O}_{4} / \mathrm{TiO}_{2}-\mathrm{Hb}$ aplicando un campo magnético externo}

Se estudiaron dos concentraciones de Nps de $\mathrm{Fe}_{3} \mathrm{O}_{4} / \mathrm{TiO}_{2}$ correspondientes a 8 y $12 \mathrm{mg} \mathrm{ml}^{-1}$, y se mantuvieron constantes las otras variables, en el shaker: concentración de $\mathrm{Hb}_{\mathrm{be}} 0,8 \mathrm{~g} \mathrm{l}^{-1}$, temperatura de $25^{\circ} \mathrm{C}$, agitación igual a $110 \mathrm{rpm}$, y tiempo de contacto con la $\mathrm{Hb}$ de 24 horas. Además, durante la remoción del complejo $\mathrm{Fe}_{3} \mathrm{O}_{4} / \mathrm{TiO}_{2}-\mathrm{Hb}$ no se varía el tiempo de acción, respectivamente 1, 24 y 48 horas ni la intensidad del campo magnético externo, igual a 1 unidad.

El espectro de UV-VIS para las soluciones con $\mathrm{Hb}$ se determina mayoritariamente por sus grupos alostéricos. La $\mathrm{Hb}$ contiene en su estructura 4 grupos prostéticos denominados Hemo formados por porfirinas con átomo central de hierro (II). Los diferentes espectros que se pueden estudiar de la $\mathrm{Hb}$ vienen determinados por el estado de oxidación del metal y la posición de las bandas de absorción en el espectro. Las medidas de UV-VIS se tomaron de la solución inicial de la $\mathrm{Hb}$ y de la solución del sobrenadante después de la remoción del complejo $\mathrm{Fe}_{3} \mathrm{O}_{4} / \mathrm{TiO}_{2}-\mathrm{Hb}$ por la acción del campo magnético externo. Para su comparación se realizó el ajuste previo de la concentración para valorarlas bajo las mismas condiciones.

En la Fig. 1, se presenta los espectros de absorbancia UV-VIS de la solución inicial de $\mathrm{Hb}$ en buffer pH 6,5 y de la solución del sobrenadante de la solución tratada con $\mathrm{Nps}$ de $\mathrm{Fe}_{3} \mathrm{O}_{4} / \mathrm{TiO}_{2}$ a una concentración de $8 \mathrm{mg} \mathrm{ml}^{-1}$ (Prueba 1) después de la remoción del complejo a diferentes tiempos de acción del campo magnético externo. La posición de las bandas de absorción en el espectro UV-VIS a $406 \mathrm{~nm}$ permite la valoración de las bandas hemo Soret indicando la presencia de la proteína sin detectar alguna posible degradación. Se descarta la reducción de la proteína de $\mathrm{Hb}$ (III) a $\mathrm{Hb}$ (II) por la permanencia del pico Soret a $406 \mathrm{~nm}$ y la ausencia de las bandas de absorción a 550 y $520 \mathrm{~nm}$.
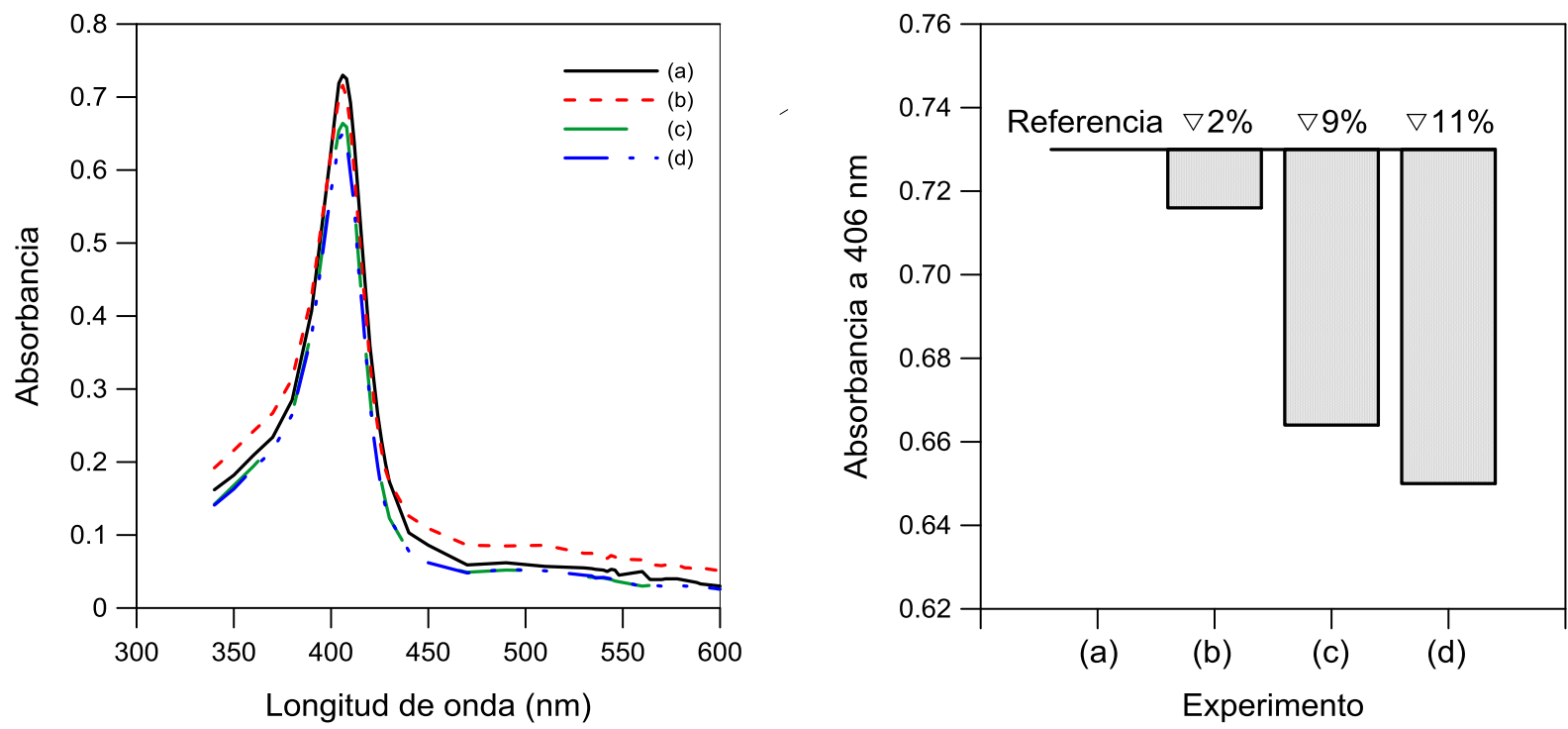

(a)

Experimento

Figura 1. Espectro UV-VIS (izquierda) y disminución de la absorbancia a $406 \mathrm{~nm}$ (derecha) de: (a) la solución inicial de $\mathrm{Hb}$ en buffer $\mathrm{pH} 6,5\left(25^{\circ} \mathrm{C}\right)$; (b) solución sobrenadante después de la adición de $\mathrm{Nps} \mathrm{Fe}_{3} \mathrm{O}_{4} / \mathrm{TiO}_{2}\left(8 \mathrm{mg} \mathrm{ml}^{-1}\right)$ y acción del campo magnético externo por 1 hora; (c) 24 horas; y (d) 48 horas. 
Después de la adsorción de la $\mathrm{Hb}$ sobre las $\mathrm{Nps}$ de $\mathrm{Fe}_{3} \mathrm{O}_{4} / \mathrm{TiO}_{2}$, éstas conservan su comportamiento magnético frente a un campo externo. La remoción de complejo $\mathrm{Fe}_{3} \mathrm{O}_{4} / \mathrm{TiO}_{2}-\mathrm{Hb}$ bajo la acción de un imán se realizó a 1, 24 y 48 horas. El efecto del tiempo de acción del campo magnético transcurrido 1 hora es mínima, la absorbencia decae solamente en un $2 \%$ con respecto a la solución inicial de $\mathrm{Hb}$. A las 24 horas se presenta una mayor remoción del complejo $\mathrm{Fe}_{3} \mathrm{O}_{4} / \mathrm{TiO}_{2}-\mathrm{Hb}$, disminuyendo el valor de absorbancia hasta en un $9 \%$, y a las 48 horas no se presenta mayor diferencia con respecto a los valores obtenidos a las 24 horas, presentando un valor del $11 \%$.

$\mathrm{Al}$ aumentar la concentración de Nps de 8 a $12 \mathrm{mg} \mathrm{ml}^{-1}$ (Prueba 2) y mantener sin modificar las otras variables se logra una mayor remoción de la $\mathrm{Hb}$, como se ilustra en la Fig. 2. Con el aumento en un $50 \%$ de $\mathrm{Nps}$ de $\mathrm{Fe}_{3} \mathrm{O}_{4} / \mathrm{TiO}_{2}$ se incrementa la cantidad de $\mathrm{Hb}$ adsorbida, la intensidad de la absorbancia disminuyen en un 10\%,15\% y $17 \%$ al transcurso de 1, 24 y 48 horas de tiempo de acción del campo magnético externo respectivamente.

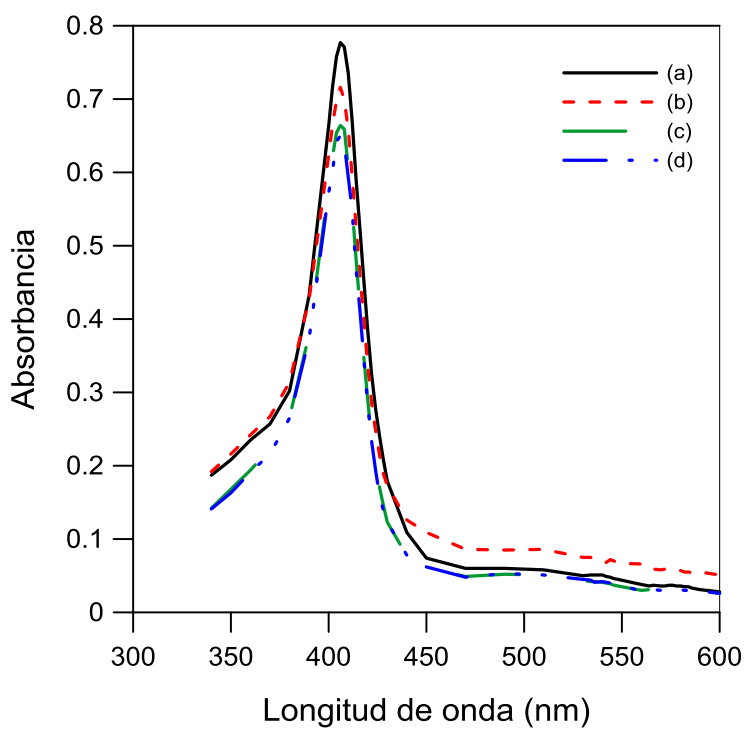

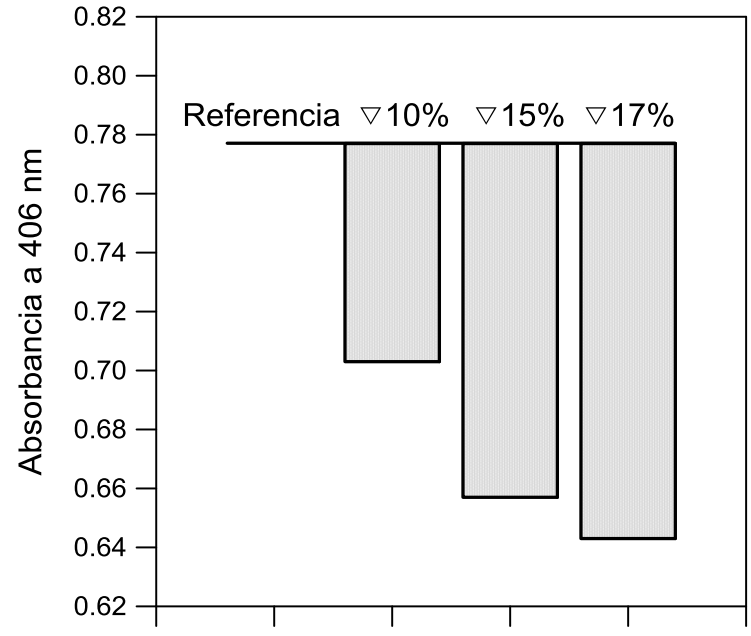

(a) (b)

(c)

Experimento

Figura 2. Espectro UV-VIS (izquierda) y disminución de la absorbancia a $406 \mathrm{~nm}$ (derecha) de: (a) solución inicial de $\mathrm{Hb}$ en buffer $\mathrm{pH}$ 6,5 $\left(25^{\circ} \mathrm{C}\right)$; (b) solución sobrenadante después de la adición de Nps $\mathrm{Fe}_{3} \mathrm{O}_{4} / \mathrm{TiO}_{2}\left(12 \mathrm{mg} \mathrm{ml}^{-1}\right)$ y acción del campo magnético externo por 1 hora, (c) 24 horas y (d) 48 horas.

La presencia remanente de $\mathrm{Hb}$ en la solución podría deberse a que la concentración de Nps $\mathrm{Fe}_{3} \mathrm{O}_{4} / \mathrm{TiO}_{2}$ no sea la suficiente para interactuar con toda la proteína presente, indicando que a las concentraciones estudiadas, el proceso de adsorción de la $\mathrm{Hb}$ sobre la superficie de las Nps de $\mathrm{Fe}_{3} \mathrm{O}_{4} / \mathrm{TiO}_{2}$ no continúa por haberse alcanzando el equilibrio de adsorción (Wang y col., 2008). Otra posible explicación para no lograr una mayor remoción de $\mathrm{Hb}$ se debe posiblemente a que la carga global de una proteína es solo un indicativo de las interacciones electrostáticas que pueden ocurrir debido a la alta concentración local de la misma carga que produce la adsorción (la $\mathrm{Hb}$ se encuentra cargada no uniformemente), mientras que por el impedimento estérico generado por el tamaño, provoca que no todos los grupos ionizados en las superficies de la proteína interactúen con la coraza de $\mathrm{TiO}_{2}$, lo que afecta la cinética de adsorción cuando las interacción electrostáticas juegan un rol primordial (Fargues y col., 1998).

\subsection{Efecto de la temperatura en la adsorción de la $\mathrm{Hb}$ sobre las $\mathrm{Nps}$ de $\mathrm{Fe}_{3} \mathrm{O}_{4} / \mathrm{TiO}_{2}$ y posterior remoción del complejo $\mathrm{Fe}_{3} \mathrm{O}_{4} / \mathrm{TiO}_{2}-\mathrm{Hb}$ aplicando un campo magnético externo}

La temperatura puede afectar directamente el proceso de adsorción de la $\mathrm{Hb}$ sobre la superficie de las Nps de $\mathrm{Fe}_{3} \mathrm{O}_{4} / \mathrm{TiO}_{2}$. Para estudiar de formar comparativa este factor, se partió de las condiciones de la Prueba 2 (temperatura de $25^{\circ} \mathrm{C}$ ) por presentar los mejores resultados y se estableció para la Prueba 3 
trabajar a una temperatura de $35^{\circ} \mathrm{C}$ sin modificar el resto de variables. El rango de la temperatura permite apreciar los cambios producidos en la estabilidad tanto del complejo $\mathrm{Fe}_{3} \mathrm{O}_{4} / \mathrm{TiO}_{2}-\mathrm{Hb}$ como de los sitios de unión sin comprometer cambios en la conformación o desnaturalización de la $\mathrm{Hb}$ (Wang y col., 2008). Los resultados de la Prueba 3 se presentan en la Fig. 3, donde se puede apreciar de acuerdo a los espectros de UV-VIS, que la remoción a la 1 hora de acción del campo magnético externo es solamente del $3 \%$, inferior al que se presentó para la prueba a $25^{\circ} \mathrm{C}(10 \%)$. Los valores para las 24 horas y 48 horas son solamente del 10 y $11 \%$ respectivamente.
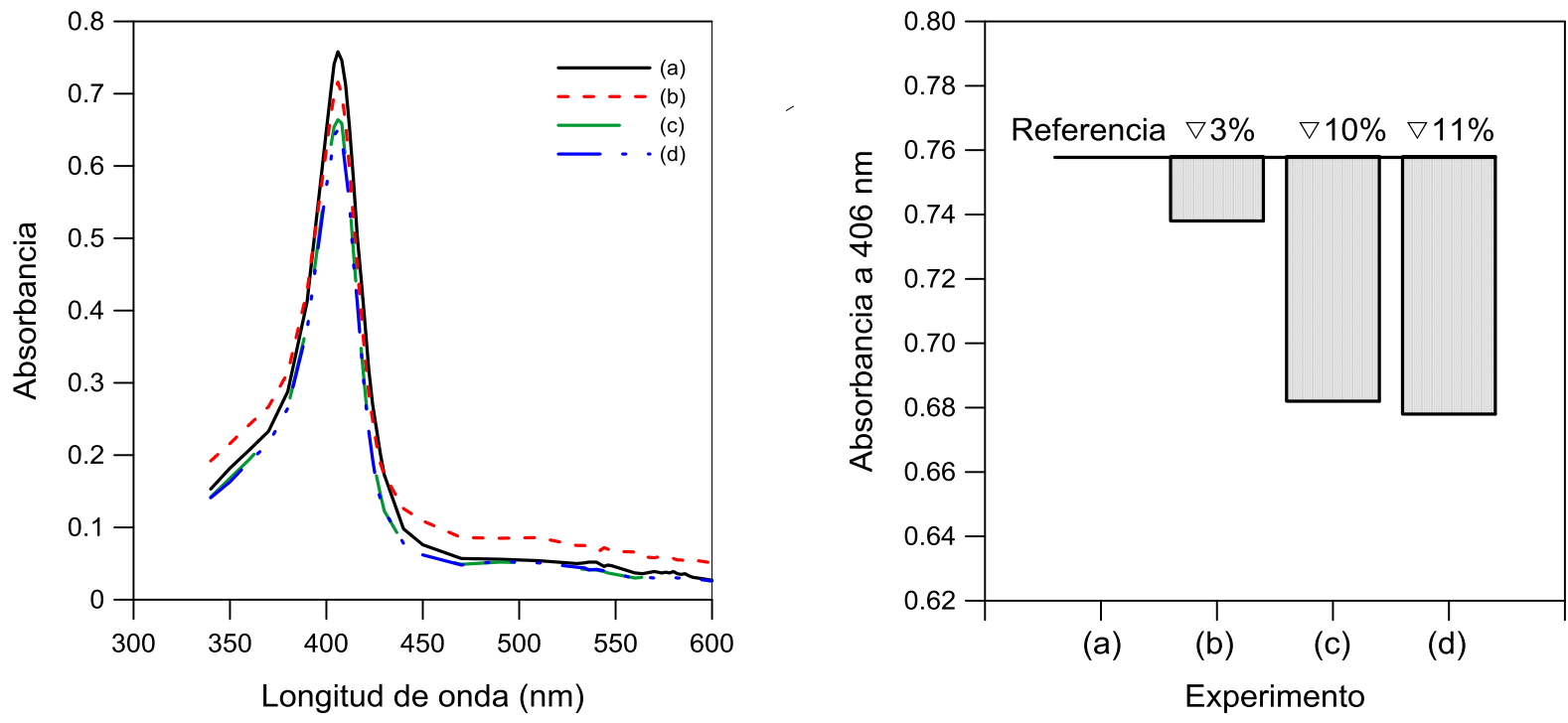

(a)

(c)

(d)

Experimento

Figura 3. Espectro UV-VIS (izquierda) y disminución de la absorbancia a $406 \mathrm{~nm}$ (derecha) de: (a) solución inicial de $\mathrm{Hb}$ en buffer $\mathrm{pH}$ 6,5 $\left(35^{\circ} \mathrm{C}\right)$; (b) solución sobrenadante después de la adición de Nps $\mathrm{Fe}_{3} \mathrm{O}_{4} / \mathrm{TiO}_{2}\left(12 \mathrm{mg} \mathrm{ml}^{-1}\right)$ y acción del campo magnético externo por 1 hora, (c) 24 horas y (d) 48 horas.

De las fuerzas de interacción no covalentes que intervienen en la unión de las proteínas con Nps en estado coloidal: puente de hidrógeno, fuerzas de van der Waals, electrostáticas e hidrofóbicas, probablemente las más importantes que interviene en la unión de la $\mathrm{Hb}$ con las $\mathrm{Nps}$ de $\mathrm{Fe}_{3} \mathrm{O}_{4} / \mathrm{TiO}_{2}$ son las fuerzas electrostáticas y las interacciones a través de puentes de hidrógeno. Por estudios de espectroscopia IR realizados por Wang y col. (2008) confirman que la unión por puente de hidrógeno $\mathrm{TiO}_{2}-\mathrm{Hb}$ a $\mathrm{pH} 7,4$ se presenta entre la superficie monocordinada de grupos $-\mathrm{OH}$ y los grupos protonados de la amina presentes en la $\mathrm{Hb}\left(>\mathrm{T}_{\mathrm{i}}-\mathrm{OH}+\mathrm{R}-\mathrm{NH}_{3}^{+} \rightarrow>\mathrm{T}_{\mathrm{i}}-\mathrm{OH} \ldots .: \mathrm{NH}_{2}-\mathrm{R}+\mathrm{H}^{+}\right)$, indicando que es la principal fuerza de interacción en la unión $\mathrm{TiO}_{2}-\mathrm{Hb}$. El incremento de la temperatura produce una menor estabilidad del complejo -si la temperatura sigue incrementando el complejo podría parcialmente descomponerse- y altera los sitios de enlace, como consecuencia se verifica un decrecimiento de la constante de enlace al incrementar la temperatura (Wang y col., 2008). Para las $\mathrm{Nps}$ de $\mathrm{Fe}_{3} \mathrm{O}_{4} / \mathrm{TiO}_{2}$ se esperaría el mismo comportamiento. Además, la temperatura contribuiría a incrementar la solubilidad de la $\mathrm{Hb}$ en el buffer, contribuyendo también en la disminución de la adsorción sobre las $\mathrm{Nps}$ de $\mathrm{Fe}_{3} \mathrm{O}_{4} / \mathrm{TiO}_{2}$. Resultados contrarios son encontrados en la literatura. Kopac y col. (2008) reportan una mayor adsorción de proteínas (albumina de suero) con el incremento de la temperatura debido al aumento en la capacidad de difusión de la proteína sobre $\mathrm{TiO}_{2}$.

Bajo estas condiciones de estudio se concluye además que la adsorción de la Hb sobre las Nps de $\mathrm{Fe}_{3} \mathrm{O}_{4} / \mathrm{TiO}_{2}$ no modifica a la $\mathrm{Hb}$, se mantiene en su forma original. Este estado de adsorción es interesante para importantes y novedosas aplicaciones en biociencia. 


\subsection{Efecto de la intensidad del campo magnético externo en la remoción del complejo $\mathrm{Fe}_{3} \mathrm{O}_{4} / \mathrm{TiO}_{2}-\mathrm{Hb}$}

Otro factor importante es el efecto que produce la intensidad del campo magnético en la remoción del complejo $\mathrm{Fe}_{3} \mathrm{O}_{4} / \mathrm{TiO}_{2}-\mathrm{Hb}$. Por esta razón, se incrementó la intensidad de campo magnético (Prueba 4) al introducir un segundo imán de iguales características que el primero. Las condiciones adicionales de la Prueba 4 son iguales a las utilizadas en la Prueba 2 pero se sensibilizó el tiempo de acción del campo magnético externo a $20 \mathrm{~min}, 40 \mathrm{~min}, 1$ hora, 24 horas y 48 horas.

En la Fig. 4 se presentan las curvas de absorbancia UV-VIS de la solución inicial de $\mathrm{Hb}$ y del sobrenadante después de la adición de las Nps de $\mathrm{Fe}_{3} \mathrm{O}_{4} / \mathrm{TiO}_{2}$ y remoción del complejo $\mathrm{Fe}_{3} \mathrm{O}_{4} / \mathrm{TiO}_{2}-\mathrm{Hb}$ por la acción del campo magnético externo a diferentes tiempos de contacto. Como se puede apreciar en la Fig. 4, no hay mayor diferencia en los valores de la absorbancia para las mediciones entre los 20 min y 1 hora de acción del campo magnético, indicando una rápida atracción del complejo $\mathrm{Fe}_{3} \mathrm{O}_{4} / \mathrm{TiO}_{2}-\mathrm{Hb}$ con el imán, obteniéndose una remoción del $14 \%$. Con tiempos muy superiores a la hora se logra mayor remoción; a las 24 horas la intensidad de la absorbancia disminuye en un $23 \%$ y a las 48 horas su valor decrece en un $28 \%$ con respecto al valor inicial. Al incrementar la intensidad del campo magnético también se está incrementando la superficie de contacto que dispone el complejo para interaccionar con el imán. Esta condición se ve favorecida enormemente a tiempos tempranos y cortos de contacto; sin embargo, a tiempos largos se logra la mayor remoción.
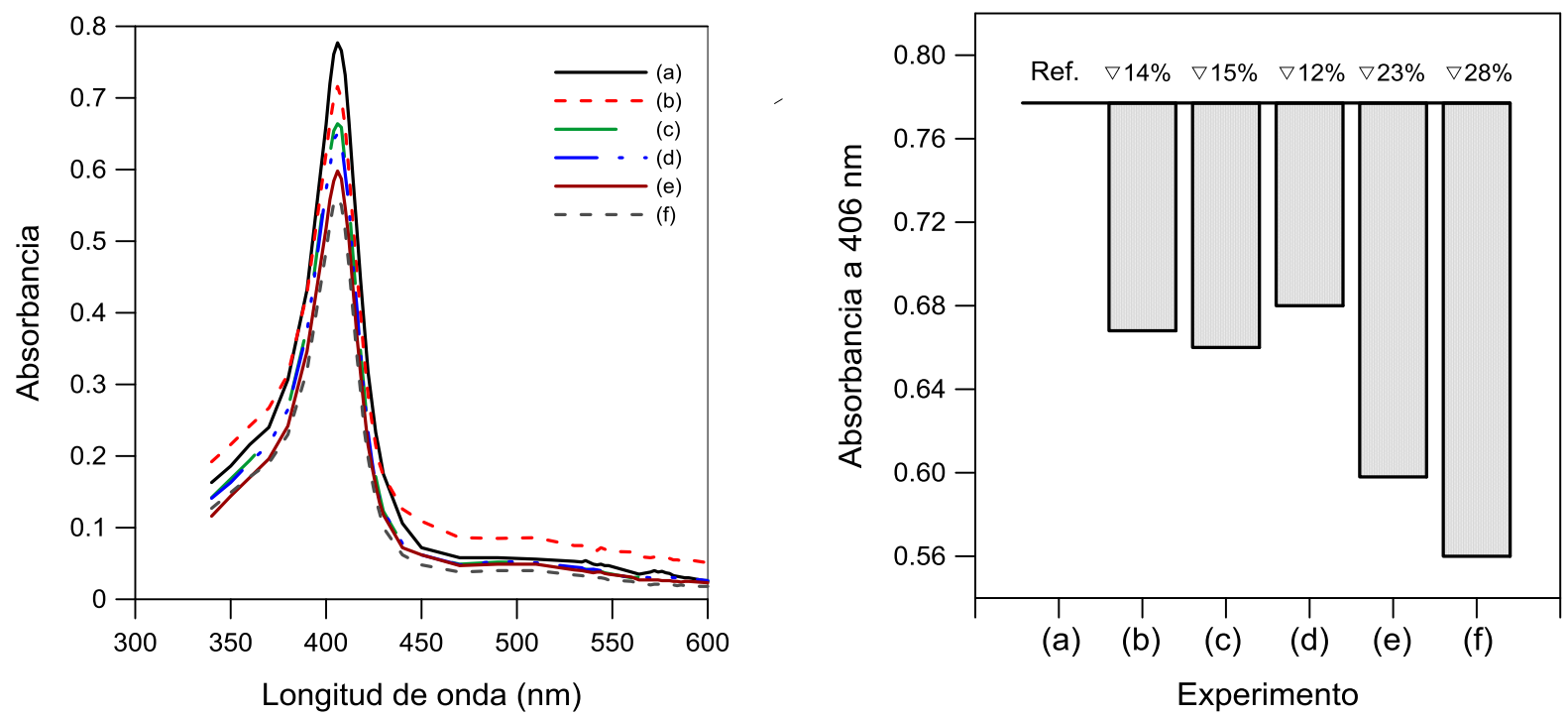

Figura 4. Espectro UV-VIS (izquierda) y disminución de la absorbancia a $406 \mathrm{~nm}$ (derecha) de: (a) solución inicial de $\mathrm{Hb}$ en buffer $\mathrm{pH} 6,5\left(25^{\circ} \mathrm{C}\right)$; (b) solución sobrenadante después de la adición de Nps $\mathrm{Fe}_{3} \mathrm{O}_{4} / \mathrm{TiO}_{2}\left(12 \mathrm{mg} \mathrm{ml}^{-1}\right)$ y acción del campo magnético externo (dos unidades) por $20 \mathrm{~min}$, (c) 40 min, (d) 1 hora, (e) 24 horas y (f) 48 horas.

\subsection{Determinación de la Demanda Bioquímica de Oxígeno $\left(\mathrm{DBO}_{5}\right)$}

$\mathrm{La} \mathrm{DBO}_{5}$ es un parámetro ampliamente usado para determinar los compuestos orgánicos biodegradables en desaguies y efluentes. La prueba permite medir la carga de los residuos y evaluar la eficiencia de remoción en sistemas de tratamiento de aguas. El ensayo da una estimación de la cantidad de oxígeno requerido durante la degradación microbiana de compuestos orgánicos en un tiempo determinado bajo condiciones especificas (Catterall y col., 2001). El ensayo más común mide el oxígeno consumido en un período de 5 días y se denomina $\mathrm{DBO}_{5}$. Este estudio, por lo tanto, permitirá relacionar los valores obtenidos de la $\mathrm{DBO}_{5}$ con la remoción de la $\mathrm{Hb}$ por el tratamiento con las Nps de $\mathrm{Fe}_{3} \mathrm{O}_{4} / \mathrm{TiO}_{2}$. Junto con la muestra a determinar la $\mathrm{DBO}_{5}$, como parámetros de control en las pruebas realizadas se incubaron las botellas que contienen: los controles de semilla, los blancos de agua de dilución y los patrones de $\mathrm{Hb}$. 


\section{Verificación del agua de dilución}

Cuando la concentración de la DBO excede la concentración de oxígeno disuelto (OD) disponible en una muestra saturada de oxígeno, es necesario diluir la muestra. El agua de dilución debe contar con las condiciones necesarias que asegure el crecimiento bacteriano. Para verificar la calidad del agua de dilución sin inóculo y la limpieza de los materiales para cada prueba se midió el OD consumido por el agua de dilución en un período de 5 días de incubación. El OD promedio obtenido inicialmente después de saturar el agua mediante burbujeo es de alrededor de $7,74 \mathrm{mg}^{-1}$ a $20^{\circ} \mathrm{C}$, medida concordante con el valor esperado para las condiciones de la ciudad de Cuenca ( $\sim 2500 \mathrm{~m}$ de altura). Después del tiempo de prueba, el valor promedio de OD es alrededor de 7,61 $\mathrm{mg}^{-1}$. La diferencia entre los valores iniciales y finales están alrededor de $0,13 \mathrm{~m} \mathrm{l}^{-1}$, valor que se encuentra dentro de los límites permitidos (menor a $0,2 \mathrm{mg} \mathrm{l}^{-1}$ ) demostrando una buena calidad del agua de dilución.

\section{Control del inóculo}

Las muestras generalmente disponen de una población bacteriana uniforme, capaz de digerir la materia orgánica existente en la muestra durante el ensayo. Para este caso en particular, a nivel de laboratorio no existe una población aerobia en la muestra original ya que se trabajó únicamente con soluciones de $\mathrm{Hb}$; por lo tanto, fue necesario adicionarla de manera artificial, condición que se logró satisfactoriamente adicionando una alícuota de una solución homogénea de E. Coli. Con el objeto de corregir el valor de OD consumido por la muestra, se debe restar a éste el consumido por el inóculo. El consumo de OD del agua de dilución más el inóculo puede estar en el intervalo de 0,6 a $1 \mathrm{mg} \mathrm{l}^{-1}$. El valor promedio obtenido para todas las pruebas está alrededor de $0,35 \mathrm{mg}^{-1}$.

\section{Chequeo con hemoglobina}

Es necesario controlar la calidad del agua de dilución, la efectividad de la semilla y la técnica analítica por mediciones de la DBO para compuestos orgánicos puros. Generalmente para este control se usa una solución estándar (150 mg de glucosa por litro y $150 \mathrm{mg}$ de ácido glutámico por litro). Pero cuando el agua contiene un constituyente mayoritario identificable que contribuye a la DBO, se debe usar este compuesto en reemplazo de la mezcla de glucosa-ácido glutámico. Para este caso en particular se tomó la solución de Hb en buffer a pH 6,5 como condición inicial y parámetro de control. Durante todas y cada una de las pruebas realizadas se incluyó la solución de $\mathrm{Hb}$ la cual tuvo en promedio un $\mathrm{DBO}_{5}$ de alrededor de $100 \mathrm{mg} \mathrm{l}^{-1}$.

\section{Ensayo de las diferentes soluciones de $\mathrm{Hb}$ tratadas con las Nps de $\mathrm{Fe}_{3} \underline{\mathrm{O}}_{4} / \underline{\mathrm{TiO}}_{2}$}

En la Tabla 1 se presentan los valores de $\mathrm{DBO}_{5}$ del sobrenadante de las diferentes soluciones de $\mathrm{Hb}$ después de la adición de las $\mathrm{Nps}$ de $\mathrm{Fe}_{3} \mathrm{O}_{4} / \mathrm{TiO}_{2}$ y posterior remoción del complejo $\mathrm{Fe}_{3} \mathrm{O}_{4} / \mathrm{TiO}_{2}-\mathrm{Hb}$ con un campo magnético externo bajo las diferentes condiciones ya reportadas y discutidas.

Tabla 1. Valores de la $\mathrm{DBO}_{5}$.

\begin{tabular}{cccc}
\hline & $\mathrm{OD}_{\text {inicial }}$ & $\mathrm{OD}_{\text {final }}$ & $\mathrm{DBO}_{5}\left(\mathrm{mg} \mathrm{l}^{-1}\right)$ \\
\hline Solución Hb & 7,14 & 1,82 & 100 \\
Prueba 2 & 7,31 & 3,68 & 62 \\
Prueba 3 & 7,12 & 4,09 & 51 \\
Prueba 4 & 7,05 & 5,47 & 22 \\
\hline
\end{tabular}

Como se puede apreciar el consumo de oxígeno al finalizar el tiempo de incubación estuvo comprendido dentro del rango del 20 a 77\% del total del oxígeno disponible. Además, los resultados indican que todas las muestras tienen una reducción del OD de más de $2 \mathrm{mg} \mathrm{l}^{-1}$ indicando un consumo significativo de oxígeno y un OD residual de más de $1 \mathrm{mg} \mathrm{l}^{-1}$ que asegura que la falta de OD no afectó la tasa de oxidación de la materia orgánica después de 5 días de incubación, considerándose datos válidos para el análisis. 
Al realizar una correlación con los datos obtenidos de las medidas espectroscópicas UV-VIS, se puede indicar que todas las soluciones de $\mathrm{Hb}$ tratadas con las $\mathrm{Nps}$ de $\mathrm{Fe}_{3} \mathrm{O}_{4} / \mathrm{TiO}_{2}$ tienen valores inferiores a la solución inicial de $\mathrm{Hb}$, al igual que los valores de $\mathrm{DBO}_{5}$. Sin embargo, por la naturaleza bioquímica de la $\mathrm{DBO}_{5}$ se hace difícil obtener resultados con una tendencia clara. Es necesario realizar más estudios para profundizar esta relación, tomando en consideración posibles efectos colaterales del tratamiento con Nps.

\section{CONCLUSIONES}

Mediante el estudio de los espectros de UV-VIS de soluciones de $\mathrm{Hb}$ en buffer $\mathrm{pH}$ 6,5 y de las soluciones del sobrenadante se comprobó la remoción por adsorción de la $\mathrm{Hb}$ sobre las Nps de $\mathrm{Fe}_{3} \mathrm{O}_{4} / \mathrm{TiO}_{2}$ aplicando un campo magnético externo. A una concentración de $8 \mathrm{mg} \mathrm{ml}^{-1}$ de Nps y a $25^{\circ} \mathrm{C}$ se logró disminuir en un $11 \%$ los valores de absorbancia. Al aumentar la concentración de las Nps a $12 \mathrm{mg} \mathrm{ml}^{-1}$, la remoción incrementa a un $17 \%$. A esta concentración se estudió el efecto de la temperatura al incrementar de 25 a $35^{\circ} \mathrm{C}$. Los valores de la absorbancia disminuyen con respecto al valor inicial, la temperatura favorecería la solubilidad de la $\mathrm{Hb}$ y disminuiría la estabilidad del complejo de las $\mathrm{Nps}$ de $\mathrm{Fe}_{3} \mathrm{O}_{4} / \mathrm{TiO}_{2}-\mathrm{Hb}$. Finalmente la variación de la intensidad del campo magnético fue estudiado; al incrementar la intensidad, la absorbancia decrece en un $28 \%$ debido al mayor valor propio de la magnitud como de la mayor superficie de contacto.

En la determinación de la $\mathrm{DBO}_{5}$, se obtuvo buenos resultados en los parámetros de control. El agua de dilución tuvo un valor de $0,13 \mathrm{mg} \mathrm{ml}^{-1}$ de OD (final - inicial) y el consumo de OD del inoculó de E. Coli estuvo alrededor de $0,35 \mathrm{mg} \mathrm{ml}^{-1}$. $\mathrm{La}^{\mathrm{DBO}}$ 估a la solución de $\mathrm{Hb}$ tuvo un valor promedio

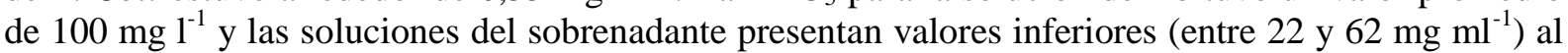
igual que las medidas espectroscópicas UV-VIS; sin embargo, por la naturaleza bioquímica propia del ensayo no se pudo establecer una relación entre estas dos mediciones.

\section{AGRADECIMIENTOS}

Los autores agradecen el soporte financiero de la DIUC (Dirección de Investigación de la Universidad de Cuenca) y además expresan su agradecimiento a la Facultad de Ciencias Químicas por la donación de la cepa de E. Coli.

\section{BIBLIOGRAFÍA}

American Water Works Association, 1999. Standard Methods for the Examination of Water and Wastewater. (20th ed.) Prepared and Published jointly by the American Public Health Association (APHA), American Water Works Association (AWWA), and the Water Environment Federation $(W E F)$.

Beydoun, D., R. Amal, 2002. Implications of heat treatment on the properties of a magnetic iron oxide - titanium dioxide photocatalyst. Mater. Sci. Eng. B, 94, 71-81.

Beydoun, D., R. Amal, G. Low, S. McEvoy, 2000. Novel Photocatalyst: Titania-Coated Magnetite. Activity and Photodissolution. J. Phys. Chem. B, 104(18), 4387-4396.

Carawan, R., J. Chambers, R. Zall, 1979. Water and wastewater management in foof processing. The North Carolina Agricultural Extension Service, NC, USA, 127 págs.

Carp, O., C. Huisman, A. Reller, 2004. Photoinduced reactivity of titanium dioxide. Prog. Solid State Chem., 32(1-2), 33-177. 
Catterall, K., K. Morris, C. Gladman, H. Zhao, 2001. The use of microorganisms with broad range substrate utilisation for the ferricyanide-mediated rapid determination of biochemical oxygen demand. Talanta, 55(6), 1187-1194.

Fargues, C., M. Bailly, G. Grevillot, 1998. Adsorption of BSA and hemoglobin on hydroxyapatite support : Equilibria and multicomponent dynamic adsorption. Adsorption, 16(4), 5-16.

Jin, B., W.-J. Bao, Z.-Q. Wu, X.-H. Xia, 2012. In situ monitoring of protein adsorption on a nanoparticulated gold film by attenuated total reflection surface-enhanced infrared absorption spectroscopy. Langmuir: the ACS Journal of Surfaces and Colloids, 28(25), 9460-9465.

Kan, X., Q. Zhao, D. Shao, Z. Geng, Z. Wang, J.-J. Zhu, 2010. Preparation and recognition properties of bovine hemoglobin magnetic molecularly imprinted polymers. J. Phys. Chem. B, 114(11), 3999-4004.

Kopac, T., K. Bozgeyik, J. Yener, 2008. Effect of $\mathrm{pH}$ and temperature on the adsorption of bovine serum albumin onto titanium dioxide. Colloid Surfaces A, 322(1-3), 19-28.

Maity, D., D.C. Agrawal, 2007. Synthesis of iron oxide nanoparticles under oxidizing environment and their stabilization in aqueous and non-aqueous media. J. Magn. Magn. Mater., 308(1), 46-55.

Mandzy, N., E. Grulke, T. Druffel, 2005. Breakage of $\mathrm{TiO}_{2}$ agglomerates in electrostatically stabilized aqueous dispersions. Powder Technol., 160(2), 121-126.

Matsui, M., A. Nakahara, A. Takatsu, 2008. In situ observation of the state and stability of hemoglobin adsorbed onto glass surface by slab optical waveguide (SOWG) spectroscopy. Int. J. Chem. Biolog. Eng., 72-75.

Salimi, A., R. Hallaj, S. Soltanian, 2007. Immobilization of hemoglobin on electrodeposited cobaltoxide nanoparticles: Direct voltammetry and electrocatalytic activity. Biophys. Chem., 130(3), 122-131.

Standard Methods Committee, 2001. Biochemical oxygen demand (BOD) (5210). Aggregate Organic Constituents, 5000, 2-13.

Topoglidis, E., C. Campbell, A. Cass, J. Durrant, 2001. Factors that affect protein adsorption on nanostructured titania films. A novel spectroelectrochemical application to sensing. Langmuir, 17(13), 7899-7906.

Vanegas, M.E., V. Vázquez, D. Moscoso, C. Cruzat, 2014. Síntesis y caracterización de nanopartículas magnéticas del tipo $\mathrm{Fe}_{3} \mathrm{O}_{4} / \mathrm{TiO}_{2}$, efecto del $\mathrm{pH}$ en la dispersión y estabilización en soluciones acuosas. Maskana, 5(1), 43-55.

Wang, Y.-Q., H.-M. Zhang, R.-H. Wang, 2008. Investigation of the interaction between colloidal $\mathrm{TiO}_{2}$ and bovine hemoglobin using spectral methods. Colloid Surfaces B, 65(2), 190-196.

Zhang, H., R.L. Penn, R.J. Hamers, J.F. Banfield, 1999. Enhanced adsorption of molecules on surfaces of nanocrystalline particles. J. Phys. Chem. B, 103(22), 4656-4662.

Zhang, M., X. He, L. Chen, Y. Zhang, 2011. Preparation and characterization of iminodiacetic acidfunctionalized magnetic nanoparticles and its selective removal of bovine hemoglobin.

Nanotechnology, 22(6), 1-9. 